\title{
Haemorrheological abnormalities in unstable angina pectoris: a relation independent of risk factor profile and angiographic severity
}

\author{
FRANZ-JOSEF NEUMANN, HARALD TILLMANNS, PETER ROEBRUCK, * \\ RAINER ZIMMERMANN, HEIDE-MARLEN HAUPT, WOLFGANG KÜBLER
}

From the Medizinische Universitätsklinik III (Kardiologie), *Institut für medizinische Biometrie und Informatik, Ruprecht-Karls Universität Heidelberg, Heidelberg, Federal Republic of Germany

SUMMARY Plasma viscosity, photometric erythrocyte aggregation index, and erythrocyte filterability were measured in 194 patients with coronary artery disease. Patients with unstable angina $(n=64)$ had a higher plasma viscosity and photometric erythrocyte aggregation index than patients with stable angina (95\% confidence intervals for the mean difference: $0.052-0 \cdot 100 \mathrm{mPa} \cdot \mathrm{s}$ for plasma viscosity, and $43 \%-72 \%$ for the photometric erythrocyte aggregation index). Multiple regression with fibrinogen, cholesterol, high density lipoprotein cholesterol, triglycerides, blood pressure, smoking habits, coronary artery score, and left ventricular ejection fraction as independent variables showed a significant partial correlation between fibrinogen and the photometric erythrocyte aggregation index $\left(r^{2}=0.20\right)$ and plasma viscosity $\left(r^{2}=0.09\right)$, between triglycerides and plasma viscosity $\left(r^{2}=0.05\right)$, and between aortic pressure and erythrocyte filterability $\left(r^{2}=0.03\right)$. Logistic regression for unstable/stable angina with the haemorrheological variables as independent variables correctly identified $72 \%$ of the patients with stable angina and $78 \%$ of those with unstable angina. Inclusion of all the variables investigated did not substantially improve the discriminative potential of the logistic regression model.

Unstable angina is associated with an impairment of blood fluidity that is essentially independent of risk factor profile and angiographic data.

There is still uncertainty on the implications of blood fluidity for symptoms and prognosis in ischaemic heart disease. Experimental data indicate that the physical properties of blood are major determinants of blood flow in the capillaries ${ }^{1-4}$ and of oxygen transport. ${ }^{5}$ The severity and extent of myocardial ischaemia produced by a given degree of coronary artery stenosis can be modified by haemorrheological alterations. Various studies have been designed to detect haemorrheological abnormalities in chronic coronary artery disease $e^{6-9}$ and in acute myocardial infarction. ${ }^{1011}$ The abnormalities described, however, may be secondary phenomena. In acute myocardial infarction, the haemorrheological abnormalities can be explained by the acute phase response induced by necrosis. ${ }^{12} 13$ In chronic coronary artery

Requests for reprints to Dr Franz-Josef Neumann, Medizinische Universitätsklinik III, Bergheimerstrasse 58, 6900 Heidelberg, Federal Republic of Germany.

Accepted for publication 10 August 1989 disease the haemorrheological alterations can be attributed to changes in risk factor profile ${ }^{14-18}$ or in the extent of coronary atherosclerosis. ${ }^{6}$

We investigated whether there is a relation between unstable angina pectoris and haemorrheological abnormalities in chronic coronary artery disease that is independent of the extent of coronary atherosclerosis, left ventricular function, and risk factor profile.

\section{Patients and methods}

\section{PATIENT SELECTION}

Patients undergoing coronary angiography for suspected coronary artery disease were eligible for the study. Exclusion criteria were: $(a)$ interfering noncardiac diseases - that is, anaemia, infection, carcinoma, collagen diseases, diabetes mellitus, thyrotoxicosis; (b) cardiac diseases other than coronary artery disease (for example dilated or hypertrophic cardiomyopathy and valvar heart disease, except for 
minor mitral regurgitation); (c) overt right or left ventricular failure; $(d)$ absence of significant coronary artery disease-that is lack of stenoses causing $\geq$ $50 \%$ narrowing in luminal diameter; $(e)$ previous coronary artery bypass surgery or percutaneous transluminal coronary angioplasty; $(f)$ myocardial infarction within the three months preceding the study; $(g)$ myocardial infarction evolving within 8 hours after withdrawal of blood for haemorrheological investigation. All patients in whom serum concentrations of creatine kinase increased with a concomitant rise in the concentration of the $\mathrm{MB}$ isoenzyme were assumed to have evolving myocardial infarction. Furthermore, patients with ST segment elevation of $>0 \cdot 1 \mathrm{mV}$ in at least one lead lasting for $>30$ minutes as well as those with intractable angina were excluded from the study because of suspected myocardial infarction. According to these criteria, 197 consecutive patients were included in the study. Three of them were subsequently excluded because of evolving myocardial infarction.

The study population was subdivided into two groups: patients with stable angina (group 1) and those with unstable angina (group 2). Unstable angina was defined by the presence of at least one of the following features: (a) angina of recent onsetthat is within six weeks or less, brought on by minimal exertion; $(b)$ crescendo angina-that is more severe, prolonged, or more frequent anginal attacks, superimposed on chronic effort angina; $(c)$ angina at rest lasting for at least 15 minutes.

The study protocol did not affect the medical treatment of the patients or early intervention in patients with unstable angina. The study was approved by the local ethics committee.

The control group consisted of 50 healthy volunteers (42 men and eight women, mean (SD) age $49 \cdot 1$ $(5 \cdot 8)$ years).

\section{RISK FACTOR PROFILE}

The risk factor profile was determined at entry into the study. Blood pressure was taken as the mean from three measurements (Riva-Rocci) on admission to hospital, according to the formula: mean blood pressure $=($ systolic blood pressure $+2 \times$ diastolic blood pressure)/3. Serum lipid concentrations were measured after a 12 hour overnight fast. Serum triglycerides and cholesterol were assayed enzymatically (Boehringer Mannheim, Mannheim, Federal Republic of Germany, triglyceride kit No 297771, cholesterol kit No 237574). High density lipoprotein cholesterol was determined after ultracentrifugation and microprecipitation. ${ }^{19}$ Patients were classified as smokers, ex-smokers, and non-smokers. Ex-smokers included all patients who had given up smoking for more than $\mathbf{4 2}$ days and less than five years. Patients who had given up smoking for more than five years were regarded as nonsmokers.

ANGIOGRAPHIC EVALUATION Coronary angiography was performed by the Judkins $\frac{\overline{\bar{c}}}{\overrightarrow{0}}$ technique. ${ }^{20}$ Multiple views, including angulated $\propto$ views, were obtained of both coronary arteries. The $\$$ angiograms were reviewed independently by two $\vec{\circ}$ experienced cardiologists who were unaware of the haemorrheological results. The luminal reduction $\vec{\omega}$ was visually estimated on the angiographic view $\frac{\rho}{2}$

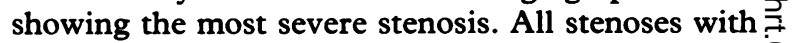
an estimated luminal reduction of at least $25 \%$ were $\stackrel{N}{N}$ scored, except for those in hypoplastic segments or $\%$ those in segments distal to total occlusions or severe $\overrightarrow{0}$ stenoses in which contrast filling was inadequate. $\vec{\circ}$ The score for each lesion was based on the estimated $\mathrm{S}$ luminal reduction as follows: $<25-50 \%$; $<50-\overrightarrow{7}$ $75 \% ;<75-90 \%$; lumen almost totally obliterated $\Phi$ but still showing anterograde flow; total occlusion. The total coronary score was obtained by taking the $\frac{7}{8}$ sum of the scores of each lesion. For calculation of left $\stackrel{\mathbb{\Phi}}{-}$ ventricular ejection fraction, end diastolic volume $\vec{\bullet}$ and end systolic volume were derived from left ${ }_{0}^{\circ}$ ventricular cineangiogram in the $30^{\circ}$ right anterior oblique view. Both ventricular volumes were determined from a beat in one of the four normal cardiac cycles after a normally conducted beat.

HAEMORRHEOLOGICAL ANALYSIS

Blood for haemorrheological investigations was taken from the antecubital vein without a tourniquet. $\vec{\mathcal{}}$ Edetic acid was used as anticoagulant. All samplesọ were obtained in the morning before coronary angiography. The haematocrit was determined by the microhaematocrit method $\left(13000 \times g\right.$ for $5 \frac{7}{\bar{\sigma}}$ minutes), and plasma viscosity by capillary vis $-\frac{0}{3}$. cometry (Coulter-Harkness viscometer ${ }^{21}$ ). Erythro-i் cyte aggregation was analysed photometrically at an adjusted haematocrit of 35 (1) \% with the miniaggregometer (Myrenne, Roetgen, Federal Republic of Germany). ${ }^{22}{ }^{23}$ The integral of the photovoltage $\frac{D}{0}$ curve in stasis for the first ten seconds after mixing was taken as a measure of erythrocyte aggregation. $\mathrm{N}$ The readings were normalised to the mean value of the control group to obtain the photometric erythrocyte aggregation index. Erythrocyte defor- $\omega$ mability was determined by a filtration method ${ }^{24} 25$ (MF4-Filtrometer, Myrenne, Roetgen, Federafo Republic of Germany). Calibrated metal microsieves $₫$ with pores of $4.3 \mu \mathrm{m}$ in diameter and $12 \mu \mathrm{m}$ in length ${ }_{T}$ were used (Myrenne, Roetgen). After removal of the buffy coat, erythrocytes were suspended in buffer

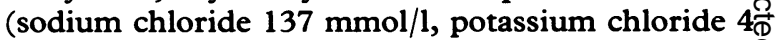
$\mathrm{mmol} / 1$, calcium chloride $1.8 \mathrm{mmol} / 1$, sodium phos $\frac{\varrho}{0}$ 
phate $0.8 \mathrm{mmol} / 1$, sodium acid phosphate $0.2 \mathrm{mmol} / 1$, magnesium sulphate $0.7 \mathrm{mmol} / 1$, glucose $5.5 \mathrm{mmol} / 1$, HEPES $8.4 \mathrm{mmol} / \mathrm{l}$, human albumin $1 \mathrm{~g} / \mathrm{l}$ ). Residual leucocytes were removed by filtering the suspension through Imugard wool (Terumo, Tokyo, Japan). In all instances, leucocyte counts were $<15 / \mu 1$. The haematocrit of the suspension was adjusted to $8 \%$. Erythrocyte deformability was measured (in relation to buffer alone) as passage through the microsieve of the erythrocyte suspension at $200 \mathrm{~Pa}$ filtration pressure ${ }^{25}$ Plasma concentrations of fibrinogen were measured by the method of Clauss. ${ }^{26}$

\section{STATISTICAL ANALYSIS}

If not indicated otherwise results are expressed as mean (SD). For the comparison of two groups, continuous variables were tested by the MannWhitney-Wilcoxon rank sum test, and the $95 \%$ confidence intervals for differences between means were calculated assuming a normal distribution. Frequencies were compared by the $\chi^{2}$ test.

The possible influence of risk factor profile and angiographic findings on haemorrheological variables was analysed by multiple linear regression. (Smoking habits were coded as 1 for non-smokers, 2 for ex-smokers, and 3 for smokers). The multiple coefficient of determination resulting from least squares estimation of the models is the part of the variability of the respective dependent variable (haemorrheological variable) that is attributable to the independent variables in the model. The contributions of single factors to the model were judged by significance tests of the respective regression coefficients.

The diagnostic value of several sets of variables for stable/unstable angina was analysed by logistic regression, which models the probability $p$ of unstable angina as $\ln (\mathrm{p} /(1-\mathrm{p}))=\Sigma \beta_{\mathrm{i}} \mathrm{x}_{\mathrm{i}}$. The $\mathrm{x}_{\mathrm{i}}$ are the independent predictor variables of the model (including a constant term), and the respective coefficients $\beta_{\mathrm{i}}$ are estimated from the data by maximum likelihood methods. Predictor variables were eliminated by stepwise variable selection if their influence was negligible in relation to the other variables. We used the estimated models to measure the probability of unstable angina for each individual member of the sample $(\hat{\mathbf{p}})$. Patients were reclassified as having stable or unstable angina, depending on whether $\hat{\mathbf{p}}$ was greater or smaller than some suitable chosen cut off point. The proportion of correctly reclassified patients is a measure of the diagnostic reliability of the predictor variables (slightly overestimated).

Both types of analysis could only be performed when a complete set of variables was known for each patient; thus some cases with missing values were omitted. Values for left ventricular ejection fraction were missing in 36 cases (because of frequent extrasystoles during cineangiography), for high density lipoprotein cholesterol in seven patients, and for fasting concentrations of all lipids in 14 patients.

\section{Results}

CHARACTERISTICS OF THE STUDY POPULATION Table 1 compares the clinical characteristics of patients with stable angina (group 1) with those of patients with unstable angina (group 2). There were no significant differences between both groups in terms of age, sex distribution, smoking habits, arterial blood pressure, serum concentrations of triglyceride, and left ventricular ejection fraction. However, the mean coronary score was significantly higher in group 2 than in group 1 ; and more patients in group 2 had more vessels affected. Likewise, serum cholesterol levels were significantly higher and serum concentrations of high density lipoprotein cholesterol were significantly lower in group 2 than in group 1. Drug treatment in the two study groups differed considerably (table 2 ). In group 2 a larger proportion of patients was treated with $\beta$ blocking agents and nitrates than in group 1. Furthermore, most of the patients with unstable angina were taking aspirin, while most of the patients with stable angina were not taking antiplatelet drugs.

HAEMORRHEOLOGICAL DATA (FIG 1)

Plasma viscosity (p $<0.001$ ) (fig 1 b), photometric

Table 1 Characteristics (mean (SD)) of the study population

\begin{tabular}{|c|c|c|c|}
\hline Variable & $\begin{array}{l}\text { Group 1 } \\
(n=130)\end{array}$ & $\begin{array}{l}\text { Group } 2 \\
(n=64)\end{array}$ & Significance \\
\hline $\begin{array}{l}\text { Age } \\
\text { Males }\end{array}$ & $\begin{array}{l}54 \cdot 6(7 \cdot 6) \\
\mathrm{n}=108(82 \%)\end{array}$ & $\begin{array}{l}52 \cdot 7(6 \cdot 9) \\
n=52(81 \%)\end{array}$ & $\begin{array}{l}\text { NS } \\
\text { NS }\end{array}$ \\
\hline $\begin{array}{c}\text { Systolic BP } \\
\text { (mm Hg) } \\
\text { Diastolic BP }\end{array}$ & $134(18)$ & $129(16)$ & NS \\
\hline (mm Hg) & $84(12)$ & $83(11)$ & NS \\
\hline $\begin{array}{l}\text { Triglycerides } \\
\text { (mg/dl) }\end{array}$ & $207(141)$ & $212(153)$ & NS \\
\hline $\begin{array}{l}\text { Cholesterol } \\
\text { (mg/dl) }\end{array}$ & $240(50)$ & $259(58)$ & $p<0.05$ \\
\hline $\begin{array}{l}\text { (mg/dl) } \\
\text { Smoking habits: }\end{array}$ & $39(13)$ & $35(13)$ & $\begin{array}{l}\mathrm{p} \\
\mathrm{NS}\end{array}$ \\
\hline $\begin{array}{l}\text { Smokers } \\
\text { Ex-smokers } \\
\text { Non-smokers } \\
\text { Number of }\end{array}$ & $\begin{array}{l}\mathrm{n}=46(35 \%) \\
\mathrm{n}=38(24 \%) \\
\mathrm{n}=47(36 \%)\end{array}$ & $\begin{array}{l}\mathrm{n}=17(27 \%) \\
\mathrm{n}=20(31 \%) \\
\mathrm{n}=23(36 \%)\end{array}$ & \\
\hline $\begin{array}{l}\text { diseased vessels: } \\
1 \\
2 \\
3\end{array}$ & $\begin{array}{l}n=74(57 \%) \\
n=31(24 \%) \\
n=26(20 \%)\end{array}$ & $\begin{array}{l}\mathrm{n}=17(27 \%) \\
\mathbf{n}=25(39 \%) \\
\mathrm{n}=22(34 \%)\end{array}$ & $\mathrm{p}<0.001$ \\
\hline $\begin{array}{l}\text { Coronary score } \\
\text { LV-EF }(\%)\end{array}$ & $\begin{array}{l}7 \cdot 1(5 \cdot 3) \\
58(20)\end{array}$ & $\begin{array}{l}8 \cdot 7(5 \cdot 5) \\
54(22)\end{array}$ & $\stackrel{p}{\text { NS }}<0.01$ \\
\hline
\end{tabular}

Group 1, patients with stable angina; group 2, patients with unstable angina; BP, blood pressure; LV-EF, left ventricular ejection fraction. 

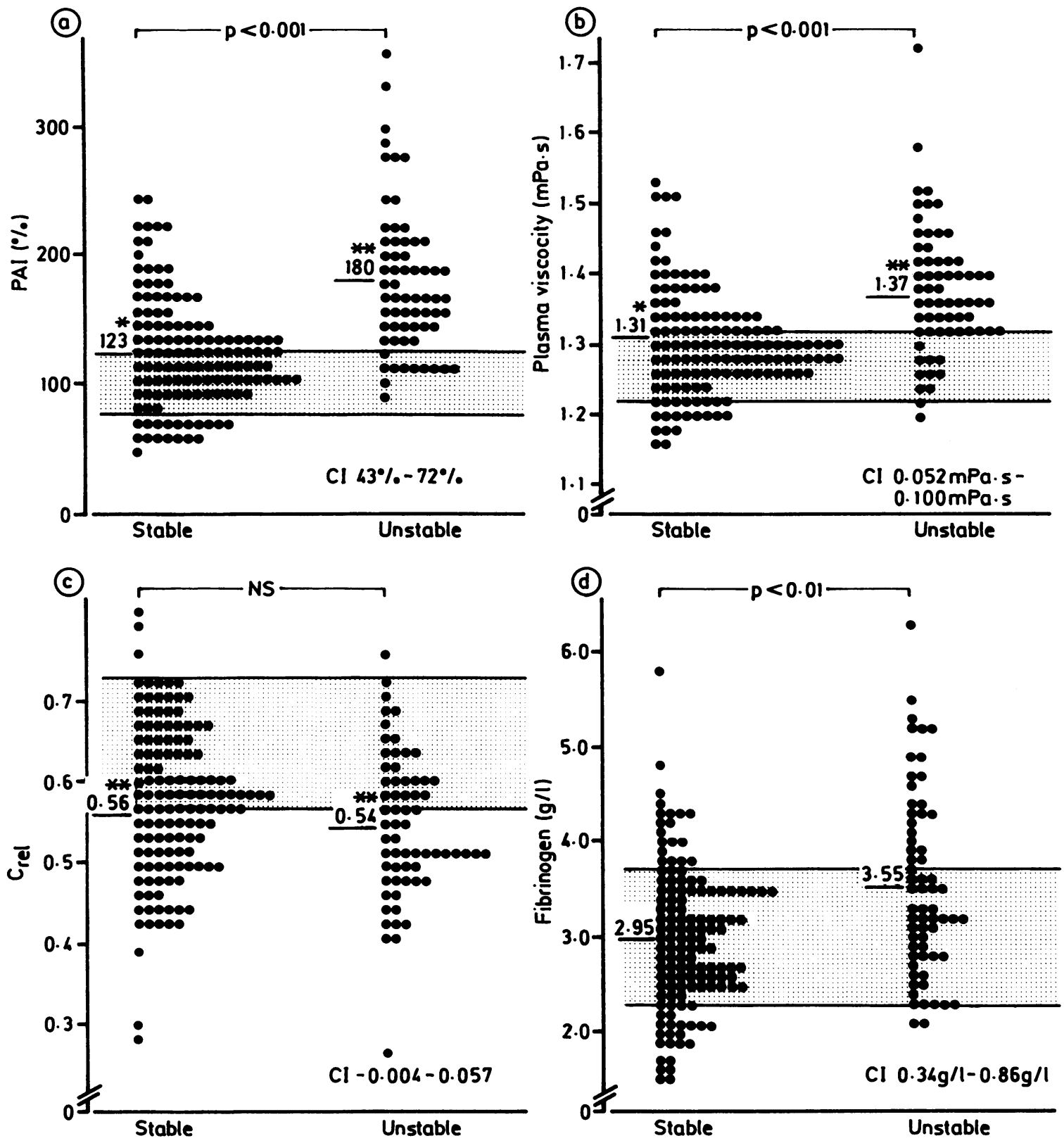

Fig 1 Haemorrheological variable ( $a-c$ ) and plasma fibrinogen concentration (d) in stable (group 1) and in unstable angina pectoris (group 2). The means for each group are shown as numerical values and are indicated graphically by horizontal lines. The hatched area represents mean \pm standard deviation of normal controls. The level of significance for the difference in means between a study group and the control group is indicated $\star_{p}<0.05 ;{ }^{\star} p<0.001 . C_{\text {rel }}$, relative conductance of the microsieve at $200 \mathrm{~Pa} ; \mathrm{CI}, 95 \%$ confidence interval for the difference in means between group 1 and $2 ; P A I$, photometric erythrocyte aggregation index. 
Table 2 Drug treatment in the study population (number $(\%))$

\begin{tabular}{lrllll}
\hline Treatment & $\begin{array}{l}\text { Group 1 } \\
(n=130)\end{array}$ & \multicolumn{2}{c}{$\begin{array}{l}\text { Group 2 } \\
(n=64)\end{array}$} \\
\hline $\begin{array}{l}\beta \text { Blocking agents } \\
\text { Calcium antagonists }\end{array}$ & 113 & $(86)$ & 62 & $(97)$ & $\mathrm{p}<0.05$ \\
Nitrates: & 94 & $(72)$ & 47 & $(73)$ & $\mathrm{NS}$ \\
$\quad$ Long acting oral & 101 & $(77)$ & 52 & $(81)$ & $\mathrm{p}<0.01$ \\
$\quad$ Intravenous & 0 & $(0)$ & 9 & $(14)$ & $\mathrm{p}<0.001$ \\
Aspirin & 14 & $(11)$ & 62 & $(97)$ & $\mathrm{p}$ \\
\hline
\end{tabular}

Group 1, patients with stable angina; group 2, patients with unstable angina.

erythrocyte aggregation indices $(p<0.001)$ (fig 1 a), and fibrinogen concentrations ( $p<0.001$ ) (fig 1 d) were significantly higher in patients with unstable angina than in patients with stable angina. The differences between the sample means in stable and unstable angina were $0.060 \mathrm{mPa} \cdot \mathrm{s}(95 \% \mathrm{CI} 0.052$ $0.100 \mathrm{mPa} \cdot \mathrm{s}$ ) for plasma viscosity, $59 \%$ with a $95 \%$ confidence interval from $43 \%$ to $72 \%$ for the photometric erythrocyte aggregation index, and 0.60 $\mathrm{g} / 1$ with a $95 \%$ confidence interval from $0.34 \mathrm{~g} / 1$ to $0.86 \mathrm{~g} / 1$ for fibrinogen. There was no significant difference in haematocrit or erythrocyte filterability (fig $1 \mathrm{c}$ ) between the two study groups. In both study groups, mean plasma viscosity and mean photometric aggregation index were significantly higher than in the controls, while mean erythrocyte filterability was significantly diminished. Fibrinogen concentrations were significantly increased only in patients with unstable angina. Haematocrit was not different in the three groups.

RELATION OF RISK FACTOR PROFILE AND ANGIOGRAPHIC DATA TO HAEMORRHEOLOGICAL VARIABLES

Multiple linear regression (table 3 ) showed that the risk factor profile (mean aortic pressure, smoking habits, serum triglycerides, cholesterol, high density lipoprotein cholesterol, and plasma fibrinogen) and angiographic data (coronary score, left ventricular ejection fraction) accounted for $24 \%$ of the variability in plasma viscosity, for $32 \%$ of the variability in photometric erythrocyte aggregation index, and for $7 \%$ of the variability in erythrocyte filterability. The only variables that significantly influenced haemorrheological variables were: fibrinogen which affected plasma viscosity and the photometric erythrocyte aggregation index; to a minor extent triglycerides, which affected plasma viscosity; and mean aortic pressure, which affected erythrocyte filterability.

\section{LOGISTIC REGRESSION}

We analysed three models of stepwise logistic regression with unstable angina as the dependent variable. The first model included the haemorrheological variables (plasma viscosity, photometric erythrocyte aggregation index, erythrocyte filterability, fibrinogen level) as independent variables. Fibrinogen was eliminated because it had a negligible additional influence. Figure 2 shows the discrimination between stable and unstable angina achieved by the first model. Maximal discrimination for recognising unstable angina gave a sensitivity of $78 \cdot 1 \%(50 / 64)$ and a specificity of $72 \cdot 3 \%(94 / 130)$. This was accomplished with a cut off point of 0.31 for the estimated probability of unstable angina. Calculation of the same model in which we considered only cases with complete data for risk factors and angiographic variables gave similar results-at a cut off point of 0.31 the sensitivity for unstable angina was $76.6 \%$ (36/47) and the specificity was 75.3\% (73/97). Again fibrinogen provided no significant information in addition to the other variables in the model.

Table 3 Multiple linear regression

\begin{tabular}{|c|c|c|c|c|c|c|}
\hline & \multicolumn{6}{|c|}{ Dependent variable } \\
\hline & \multirow{2}{*}{\multicolumn{2}{|c|}{$\begin{array}{l}\text { Viscosity: } r^{2}=0.238 \\
\text { Independent variable }\end{array}$}} & \multicolumn{2}{|c|}{$P A I: r^{2}=0.315$} & \multicolumn{2}{|c|}{$C_{r e l}: r^{2}=0.074$} \\
\hline & & & & & & \\
\hline & Partial $r^{2}$ & $p$ & Partial $r^{2}$ & $p$ & Partial $r^{2}$ & $p$ \\
\hline $\begin{array}{l}\text { Fibrinogen } \\
\text { Triglycerides } \\
\text { Cholesterol } \\
\text { High density lipoprotein cholesterol } \\
\text { Mean blood pressure } \\
\text { Smoking habits } \\
\text { Coronary score } \\
\text { Ejection fraction }\end{array}$ & $\begin{array}{l}0.09 \\
0.05 \\
0.00 \\
0.01 \\
0.00 \\
0.01 \\
0.02 \\
0.01\end{array}$ & $\begin{array}{l}0.01 \\
0.01 \\
0 \cdot 81 \\
0 \cdot 19 \\
0 \cdot 63 \\
0 \cdot 35 \\
0 \cdot 09 \\
0 \cdot 20\end{array}$ & $\begin{array}{l}0 \cdot 20 \\
0.00 \\
0.01 \\
0.01 \\
0 \cdot 01 \\
0 \cdot 00 \\
0 \cdot 00 \\
0 \cdot 01\end{array}$ & $\begin{array}{l}0.01 \\
0 \cdot 63 \\
0 \cdot 14 \\
0 \cdot 10 \\
0 \cdot 24 \\
0 \cdot 61 \\
0 \cdot 61 \\
0 \cdot 10\end{array}$ & $\begin{array}{l}0.03 \\
0.00 \\
0.01 \\
0.01 \\
0.03 \\
0.00 \\
0.00 \\
0.00\end{array}$ & $\begin{array}{l}0 \cdot 06 \\
0.94 \\
0 \cdot 22 \\
0.39 \\
0.04 \\
0 \cdot 67 \\
0 \cdot 54 \\
0.59\end{array}$ \\
\hline
\end{tabular}

$r^{2}$, coefficient of determination for the model containing all independent variables; partial $r^{2}$, partial coefficient of determination for the model containing all independent variables; $\mathrm{C}_{\text {rel }}$, relative conductance of the microsieve at $200 \mathrm{~Pa}$; $\mathrm{PAI}$, photometric aggregation index. 

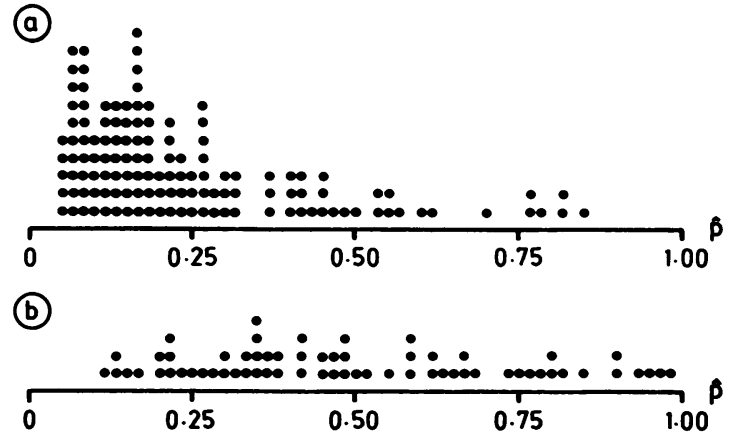

Fig 2 Results of the stepwise logistic regression for unstable angina with plasma viscosity, photometric erythrocyte aggregation index, erythrocyte filterability, and fibrinogen concentration as independent variables (after elimination of fibrinogen concentration). (a) Predicted probabilities of unstable angina for group 1 (stable angina). (b) Predicted probabilities of unstable angina for group 2 (unstable angina).

The second model included the haemorrheological variables in the first model as well as risk factors (mean aortic pressure; smoking habits; and plasma concentrations of triglycerides, cholesterol, and high density lipoprotein cholesterol) and angiographic variables (coronary score, left ventricular ejection fraction) as independent variables. Smoking habits, fibrinogen concentrations, and lipid concentrations were eliminated from the model because their additional influence was negligible. Discrimination was greatest at a cut off point of 0.31 for the estimated probability of unstable angina (sensitivity $78.7 \%$ (37/47) and specificity of $76 \cdot 3 \%$ (74/97)).

The third model included risk factors and angiographic data as independent variables. The following variables were eliminated because they made an insignificant additional contribution to the regression: triglycerides, high density lipoprotein cholesterol, smoking habits, and left ventricular ejection fraction. Discrimination was greatest at a cut off point of 0.31 for the estimated probability of unstable angina-with a sensitivity of $63.8 \%(30 / 47)$ and a specificity of $63.9 \%(62 / 97)$.

\section{Discussion}

This study is the first to show a relation between impaired blood fluidity and the clinical manifestation of coronary artery disease, independent of the extent of coronary atherosclerosis, left ventricular function, and risk factor profile.

HAEMORRHEOLOGICAL ALTERATIONS Chronic coronary artery disease is associated with changes in plasma viscosity, erythrocyte aggregation, $\vec{c}$ and erythrocyte filterability that impair blood fluidity. Plasma viscosity and erythrocyte aggregation were higher in unstable angina than in stable $\bar{C}$ angina. These haemorrheological abnormalities can be used to predict unstable angina: $78 \cdot 1 \%$ of the patients with unstable angina were correctly identified by a logistic regression model that included plasma viscosity, erythrocyte aggregation, and erythrocyte filterability.

\section{RELATION TO RISK FACTOR PROFILE AND ANGIOGRAPHIC DATA}

The relation between haemorrheological variables and unstable angina was independent of differences $\sigma$ in risk profile and angiographic data between the groups with unstable and stable angina. This conclusion is supported by two lines of evidence. Firstly, 9 the accuracy of the logistic regression model for unstable angina that included risk factors and angiographic data improved when the haemorrheological variables were added, whereas the accuracy of the model with haemorrheological variables was not significantly improved by the inclusion of risk factors and angiographic data. Secondly, risk factors and angiographic variables had little influence on multiple linear regression for the haemorrheological variables; and most of this influence was attributable to fibrinogen. The logistic regression model including haemorrheological variables and fibrinogen, however, did not improve the discrimination between stable and unstable angina as compared with a regression model including just the haemorrheological variables. The same was true for triglycerides, one of the two other variables with a significant influence on one of the haemorrheological variables. The second, mean blood pressure, was retained in the logistic regression model. None the less, mean blood pressure accounted for only $3 \%$ of the variability in erythrocyte filterability and was not significantly related to plasma viscosity or red cell aggregation.

INFLUENCE OF THE METHOD
Apparent whole blood viscosity as a function of shear has been widely used in previous studies; the advantage of this approach is that it assesses the combined rheological effects of all blood $N$ constituents. Apparent whole blood viscosity as it is $\underset{\omega}{\tilde{N}}$ measured in rotational viscometers, however, only $\widetilde{\sigma}$ reflects the blood flow behaviour in large con- 0 ductance vessels, which contribute little to vascular $\mathbb{\Phi}$ resistance. ${ }^{27}$ Furthermore, at low shear stresses the $\stackrel{\mathscr{?}}{?}$ results of apparent whole blood viscosity may be 0 erroneous because of considerable artefacts caused by phase separation within the viscometer. ${ }^{28} 29$ For these reasons, in the present study we analysed the 
haemorrheological factors that directly interfere with flow in the microcirculation. ${ }^{27}{ }^{30}$ Among these factors those of major importance are systemic haematocrit, plasma viscosity, erythrocyte aggregation, and erythrocyte deformability. ${ }^{27} 3031$

Drug treatment was not standardised in the present study; hence, antianginal treatment was intensified with increasing clinical severity of the disease. In various studies, nitrates, ${ }^{32} 33$ calcium antagonists, ${ }^{34}{ }^{35}$ and $\beta$ blocking agents ${ }^{36-39}$ were found to have no effect or even a beneficial effect on blood fluidity. Similarly, aspirin had no effect on erythrocyte deformability and whole blood viscosity. ${ }^{40}$ Thus the haemorrheological alterations seen in patients with stable and unstable angina cannot be attributed to drug treatment.

Several groups described fibrinogen as an important haemorrheological variable because of its influence on plasma viscosity and, in particular, on erythrocyte aggregation. ${ }^{62829}$ Furthermore, fibrinogen was identified as a cardiovascular risk factor. $^{41}$ In the present study fibrinogen was, therefore, treated as a cardiovascular risk factor in the multiple linear regression, in order to assess the interrelated influence of the various risk factors on the haemorrheological variables. Because the relation between unstable angina and raised values for haemorrheological variables might only be caused by increased fibrinogen concentrations, fibrinogen was included in the logistic regression analysis as well as the haemorrheological variables.

\section{PATHOGENETIC IMPLICATIONS}

Unstable angina is associated with changes in blood properties affecting not only coagulability ${ }^{42}$ and platelet function, ${ }^{43}$ but also blood fluidity, as shown in the present study. Secondary effects caused by changes in risk factor profile, angiographic severity of coronary artery narrowing, or left ventricular function are excluded by the present study.

Never the less, the present study does not resolve the principal question, which is "are the haemorrheological changes associated with unstable angina a cause or an effect of the disease'? The haemorrheological changes in patients with unstable angina may be partly related to an acute phase response ${ }^{121344}$ caused by ischaemic myocardial injury. Fibrinogen, one of the acute phase reactants, ${ }^{1213}$ is known to enhance plasma viscosity and, in particular, erythrocyte aggregation..$^{289}$ In the present study, only $9 \%$ of the variability in plasma viscosity and only $20 \%$ of the variability in erythrocyte aggregation were attributed to changes in fibrinogen concentration. Furthermore, multiple logistic regression showed that the relation between plasma viscosity and erythrocyte aggregation and unstable angina was much closer than that with fibrinogen concentration. The haemorrheological alterations, therefore, could have a direct impact on unstable angina. Patients with unfavourably altered haemorrheological variables might be at increased risk of developing unstable angina superimposed on the stable course of the disease. This view is supported by experimental data showing that at low perfusion pressures, as in the post-stenotic areas, a rise in blood viscosity further curtails capillary perfusion. ${ }^{4}$ The haemorrheological abnormalities in unstable angina may, therefore, further impede flow of nutrients in the post-stenotic myocardial microcirculation.

The study was supported by a grant from the Wilhelm Sander-Stiftung, Munich, Federal Republic of Germany.

\section{References}

1 Dormandy JA. Influence of blood viscosity on blood flow and the effect of low molecular weight dextran. Br Med J 1971;iv:716-9.

2 Wells R. Microcirculation and coronary blood flow. Am $J$ Cardiol 1972;29:847-50.

3 Chien S. Hemorheology in clinical medicine. Clin Hemorheol 1982;2:137-42.

4 Most AS, Ruocco NA, Gewirtz H. Effect of a reduction in blood viscosity on maximal myocardial oxygen delivery distal to a moderate coronary stenosis. Circulation 1986;74:1085-92.

5 Finch CA, Lenfant C. Oxygen transport in man. $N$ Engl J Med 1972;286:407-9.

6 Lowe GDO, Drummond MM, Lorimer AR, et al. Relation between extent of coronary artery disease and blood viscosity. $\mathrm{Br} \mathrm{Med} J$ 1979;i:673-4.

7 Fuchs J, Weinberger I, Rotenberg Z, et al. Plasma viscosity in ischemic heart disease. Am Heart $J$ 1984; 108:435-9.

8 Low J, Dodds AJ, McGrawth M, Biggs JC. Red cell deformability and other haemorrheologic variables in stable coronary artery disease. Thromb Res 1985;38: 269-74.

9 Rainer CR, Kawanishi DT, Chandaratna AN, et al. Changes in blood rheology in patients with stable angina pectoris as a result of coronary artery disease. Circulation 1987;76:15-20.

10 Jan KM, Chien S, Bigger JT. Observations on blood viscosity changes after myocardial infarction. Circulation 1975;51:1079-84.

11 Dodds AJ, Boyd MJ, Allen J, Bennett ED, Flute PT, Dormandy JA. Changes in red cell deformability and other haemorrheological variables after myocardial infarction. Br Heart J 1980;44:508-11.

12 Kushner I. The phenomenon of the acute phase response. Ann NY Acad Sci 1982;389:39-48. 
13 Dinarello CA. Interleukin I and the pathogenesis of the acute-phase response. $N$ Engl $J$ Med 1984;311: 1413-8.

14 Leonhard H, Arntz HR, Klemens UH. Studies of plasma viscosity in primary hyperlipoproteinaemia. Atherosclerosis 1977;28:29-40.

15 Lowe GDO, McArdle BM, Stromberg P, Lorimer AR, Forbes CD, Prentice CRM. Increased blood viscosity and fibrinolytic inhibitor in type II hyperlipoproteinaemia. Lancet 1982;i:472-5.

16 Letcher RL, Chien S, Pickering TG, Laragh JH. Elevated blood viscosity in patients with borderline essential hypertension. Hypertension 1983;5:757-62.

17 Isles C, Lowe GDO, Rankin BM, et al. Abnormal haemostasis and blood viscosity in malignant hypertension. Thromb Haemost 1984;52:253-5.

18 Belch JJ, McArdle BM, Burns P, Lowe GDO, Forbes CD. The effects of acute smoking on platelet behaviour, fibrinolysis and haemorrheology in habitual smokers. Thromb Haemost 1984;51:6-8.

19 Kohlmeier M. Simplified lipoprotein analysis by means of ultracentrifugation. Arztl Lab 1986;32:46-52.

20 Judkins MP. Selective coronary angiography: a percutaneous transfemoral technique. Radiology 1967;89: 815-24.

21 Harkness J. A new instrument for the measurement of plasma viscosity. Lancet 1963;ii:280-1.

22 Volger E, Schmid-Schönbein H, VonGosen J, Klose HJ, Kline KA. Microrheology and light transmission of blood. IV. The kinetics of artificial red cell aggregation induced by dextran. Pflugers Arch 1975; 354:319-37.

23 Kiesewetter H, Radtke H, Schneider R, Mussler K, Scheffler A, Schmid-Schönbein H. The miniaggregometer: a new apparatus for the rapid quantification of the extent of erythrocyte aggregation. Biomed Tech (Berlin) 1982;27:209-13.

24 Teitel P. Basic principles of the filterability test and analysis of erythrocyte flow behavior. Blood Cells 1979;3:55-70.

25 Neumann FJ, Haupt H, Zimmermann R, Tillmanns $\mathbf{H}$. Metal microsieves in red cell filtration. Clin Hemorheol 1989;9:125-37.

26 Clauss A. Gerinnungsphysiologische Schnellmethode zur Bestimmung des Fibrinogens. Acta Haematol (Basel) 1957;17:237-42.

27 Schmid-Schönbein H. Microrheology of erythrocytes, blood viscosity and the distribution of blood in the microcirculation. In: Guyton AC, Cowley AW, eds. International Reviews in Physiology vol 9. Cardiovascular physiology II. Baltimore: University Park Press, 1976:1-62.

28 Merrill EW. Rheology of blood. Physiol Rev 1969;49: 863-88.

29 Chien S, Usami S. Shear dependent interactions of plasma proteins with erythrocytes in blood rheology.
Am J Physiol 1970;219:143-53.

30 Schmid-Schönbein $\mathbf{H}$, Rieger $\mathbf{H}$, Fischer $T$. Blood $\leftarrow$ fluidity as a consequence of red cell fluidity: flow properties of blood and flow behavior of blood in vascular diseases. Angiology 1980;31:301-19.

31 Schmid-Schönbein H, Gallasch G, von Gosen J, Volger E, Klose HJ. Red cell aggregation in blood flow. II. Effect on apparent viscosity of blood. Klin Wochenschr 1976;54:159-67.

32 Hossmann V, Wegener H, Wegener B, Saborowski F, क Cäsar K. Hemorrheological and hemodynamic effectso of ISDN in essential hypertension and obliterative arterial disease. In: Lichtlen PR, Enge $\mathrm{HJ}$, Schrey $\mathrm{H}_{,}, \overrightarrow{\mathrm{W}}$ Swan HJC, eds. Nitrates III. Berlin, Heidelberg, New York: Springer, 1981:263-70.

33 Ehrly AM, Landgraf $\mathbf{H}$. Einfluß von Isosorbitdinitraț auf die Fliesseigenschaften des Blutes bei Patientenó mit chronischer arterieller Verschlusskrankheit. In:A Ehrly AM, ed. Therapie mit hämorheologisch wirksamen Substanzen. Munich, Berne, Vienna:음 Zuckerschwerdt, 1984:145-8.

34 Volger E, Pfafferott C, Bauersachs R, Busch U, Gaim F, Stoiber M. Hemorrheological aspects of myocardia $\mathbb{D}$ ischaemia. Clin Hemorheol 1986;6:229-43.

35 Volger E, Schönhärl B, Haberland S, Pfafferott C. Effect of different calcium antagonists on red blood $\stackrel{\Phi}{-}$ cell filterability [Abstract]. Biorheol 1986;23:243.

36 Boogaerts MA, Roelant C, Temmermann J, Goosenso W, Verwilchen RL. Effect of beta-blocking drugs on red cell adhesive and rheological properties. $J$ Lab Clin Med 1983;102:899-908.

37 Caimi G, Catania A, Frazzeta F, Capobianco D, Sarno A. The behaviour of the hemorrheological determi-0 nants and their trends during beta-blocker treatment. $\mathbb{Q}$ Jpn Heart $J$ 1973;24:723-9.

38 Ernst E, Roloff C, Marshall M. Beta-blocker increasesô blood fluidity. Herz und Gefässe 1984;4:470-9.

39 Waller DG. Whole blood viscosity following cardioselective beta-adrenoreceptor blockade in hypertension. Clin Hemorheol 1982;2:243-7.

40 Stäubli M, Reinhard W, Straub PW. Blood viscosity and red cell deformability after aspirin in vivo-a double blind controlled trial. Atherosclerosis 1982; 41:167-70.

41 Kannel WB, Wolf PA, Castelli WP, D'Agostino RB. Fibrinogen and risk of cardiovascular disease. JAMA 1987;258:1183-6.

42 Throux P, Latour JG, Lger-Gauthier C, Delara J.D Fibrinopeptide $A$ and platelet factor levels in unstable angina pectoris. Circulation 1987;75:156-62.

43 FitzGerald DJ, Roy L, Catello F, FitzGerald GA.の Platelet activation in unstable coronary disease. $N$ N Engl J Med 1986;315:983-9.

44 Stuart J. The acute phase reaction and haematologica $\omega$ stress reaction and haematological stress syndrome in vascular disease. Int J Microcirc 1984;3:11-9. 